Terr. Atmos. Ocean. Sci., Vol. 18, No. 5, 1011-1027, December 2007

\title{
Response of Harmful Algal Blooms to Environmental Changes in Daya Bay, China
}

\author{
Jing Yu ${ }^{1,2,3}$, Dan-Ling Tang ${ }^{1,2, ~ *}$, Im-Sang Oh ${ }^{4}$, and Li-Jun Yao ${ }^{5}$
}

(Manuscript received 4 January 2007, in final form 15 June 2007)

\begin{abstract}
Economic progress has been rapid around the Daya Bay region of the northern South China Sea (SCS) over recent decades. To investigate changes of Harmful Algal Blooms (HABs) caused by environmental situation in the bay area, the present study analyzed the occurrence of HAB and environmental conditions in Daya Bay using in situ and satellite remote sensing data for the period of 1983 - 2004. Only 14 HABs were observed during the first decade (1983 - 1993), while 55 HABs occurred during the second decade (1994 - 2004). The locations of HAB have extended from aquaculture areas to the entire bay area. In addition, the seasonality of HAB has changed from spring and autumn prior to 1994 to all year round post 1994. Changes in HAB frequency and location were found to be associated with variations in nutrients and contaminants in the bay area. Total inorganic nitrogen (TIN) was $0.021 \mathrm{mg} \mathrm{l}^{-1}$ in 1986, but had reached $0.068 \mathrm{mg} \mathrm{l}^{-1}$ by 1999 and
\end{abstract}

\footnotetext{
${ }^{1}$ Remote Sensing and Marine Ecology/Environment Group (RSMEE), Key Laboratory of Tropical Marine Environmental Dynamics, South China Sea Institute of Oceanology, Chinese Academy of Sciences, Guangzhou, China

${ }^{2}$ Graduate School of the Chinese Academy of Sciences, Beijing, China

${ }^{3}$ South China Sea Fisheries Research Institute, Chinese Academy of Fishery Sciences, Guangzhou, China

${ }^{4}$ Research Institute of Oceanography and School of Earth and Environmental Sciences, Seoul National University, Korea

5 Department of Electro-Optical Engineering, Jinan University, Guangzhou, China

* Corresponding author address: Dr. Dan-Ling Tang, Remote Sensing and Marine Ecology/Environment Group (RSMEE), Key Laboratory of Tropical Marine Environmental Dynamics, South China Sea Institute of Oceanology, Chinese Academy of Sciences, Guangzhou, China;

E-mail: lingzistdl@126.com, lingzis@scsio.ac.cn doi: 10.3319/TAO.2007.18.5.1011(Oc)
} 
the ratio of TIN/P increased also, with a peak value (18.28) in 1999. Organic contaminants have also been relatively high in recent years in Daya Bay. The seasonal extension of HAB was found to be connected partially with increased water temperature resulting from the thermal discharge of nuclear power stations. Yearly mean water surface temperature (WST) increased over the past two decades. Monthly mean WST also increased after the Daya Bay nuclear power station commenced operating in 1994, ranging from 0.2 to $2.7^{\circ} \mathrm{C}$. There were about 14 algal species recorded to have caused HABs frequently in Daya Bay, such as Scrippsiella trochoidea. The number of HAB species increased in the second decade (1994 - 2004). A warm-water favoring species Peridinium quinquecorne caused a bloom in May 1999. This was the first recorded time of this species blooming in China. These changes are associated with increases in cage aquaculture, contaminants discharged from industrial and agricultural activities, and thermal discharge from the nuclear power stations in Daya Bay.

(Key words: Harmful Algal Bloom, Water surface temperature, Nutrient, Marine ecology, Daya Bay, China)

\section{INTRODUCTION}

Daya Bay, China, is located in the northern South China Sea (SCS; Fig. 1a). It was one of the major aquaculture areas in the Guangdong province because of its excellent water quality and rich biological resources (Xu 1989). Since the operation of the first large-capacity commercial nuclear power unit in China (Daya Bay nuclear power station, DNPS) in 1994, economic developments in industries, aquaculture and agriculture in the area have rapidly expanded. The second nuclear power station (Lingao nuclear power station, LNPS) near to the DNPS also commenced first stage operations in early 2003 (http://www.cgnpc.com.cn; Fig. 1b). Other industries such as petrochemical, plastic, printing, and stevedoring are also present (Song et al. 2004). In addition, aquaculture increased dramatically from 1000 cages in 1988 to 20500 cages in 2004 (one cage is about $9 \mathrm{~m}^{2}$; Fig. 2a) involving a larger area for aquaculture and also cage density. Along with these activities, the permanent resident population around the bay doubled from 1217600 in 1979 to 2359000 in 1997 with additional 1000000 - 1200000 nonresidents (http://www.hzsin.gov.cn/).

Harmful Algal Bloom (HAB) describes the proliferation of microscopic algae, benthic or planktonic macroalgae in response to anthropogenic nutrient enrichment, leading to major ecological impacts such as the displacement of indigenous species, habitat alteration, or oxygen depletion. It is regarded as a marine catastrophe and often produces serious consequences for public health and the well being of aquatic organisms (Anderson 1994, 1995; Tang et al. 2004). The frequency of $\mathrm{HAB}$ and the amount of affected area are increasing along Chinese coasts, especially the SCS in recent years (Qian et al. 2000; Tang et al. 2003a, 2006a, b; Qi et al. 2004). One HAB event in the SCS during March and April 1998 has been reported to have 
wiped out 1500 tons of farmed fish, which was equivalent to half of the entire Hong Kong aquacultural production in 1997 (Anderson 1998). In Daya Bay, HABs also have caused considerable economic loss. For example, one HAB caused about 75 tons of farmed fish to be lost in April 1983. Another two HABs occurred in August 2000 and August 2003 resulting in losses of about US\$370000 and US\$41000, respectively (http://www.china-hab.cn). While the harmfulness of HABs is well recognized, they are generally poorly understood in terms of how changes in environmental conditions along the coast of China influence their occurrence.

With such a long history of development, well kept record of environment information, and semi-closed shape and size, Daya Bay provides an ideal case study for assessing the impacts of environmental change on algal blooms. It has already received much attention due to

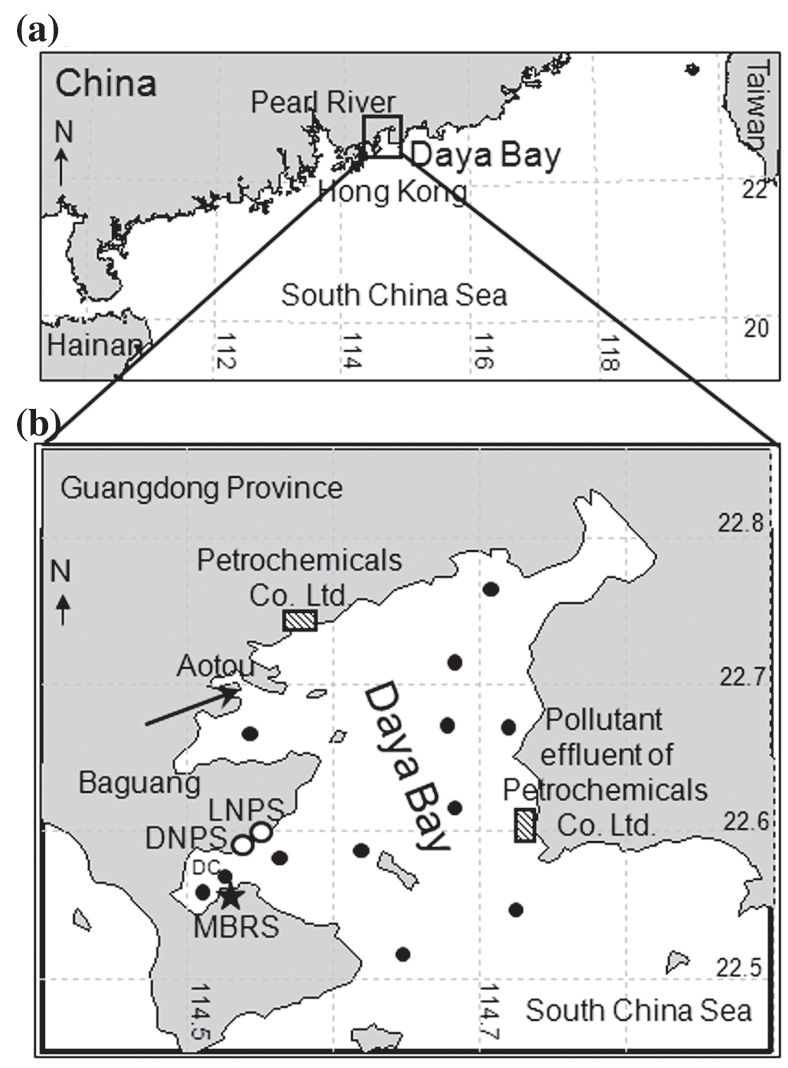

Fig. 1. (a) Location of Daya Bay (small box). (b) Daya Bay map with Daya Bay nuclear power station (DNPS) and Lingao nuclear power station (LNPS) in Dapeng Cove (DC). The two small shaded boxes: Petrochemicals Co. Ltd and their pollutant effluent. Black dots indicate the twelve survey stations. MBRS: Marine Biology Research Station. Arrow indicates the location of Peridinium quinquecorn bloom in May 1999. 


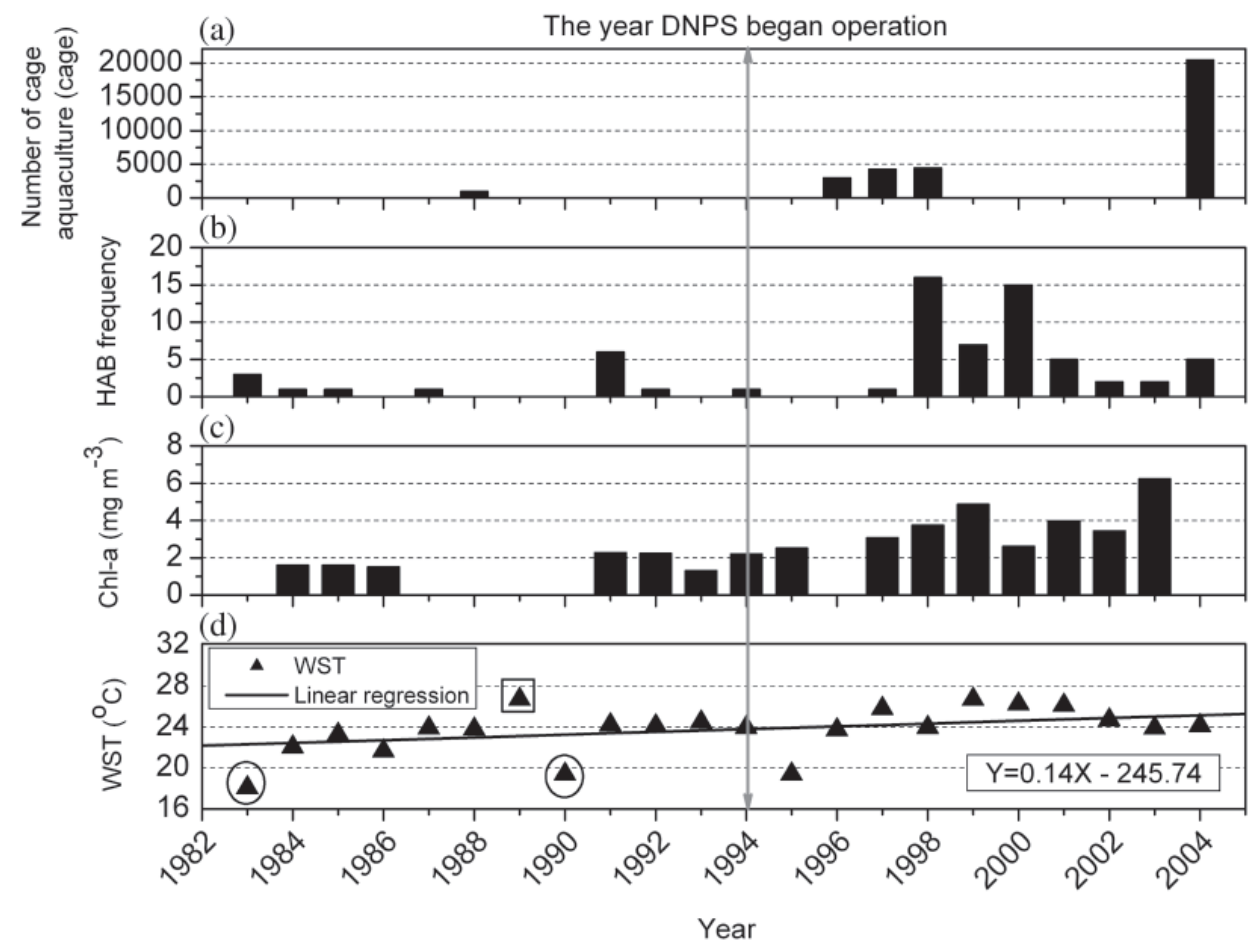

Fig. 2. (a) Number of cage aquaculture in Daya Bay, 1988 - 2004. (b) Annual records of HAB in Daya Bay, 1983 - 2004. (c) Yearly mean Chl- $a$ concentrations from in situ observation during 1984 - 2003. (d) Yearly mean water surface temperature (WST) from in situ observation during 1983 2004. Black line indicates linear regression for yearly mean WST. Grey line indicates the year when the first nuclear power station (DNPS) began operation, blank indicates no data for the year.

its environmental changes (Zhou et al. 2001; Zeng et al. 2002; Tang et al. 2003b; Zhou and Maskaoui 2003; Song et al. 2004). Studies on the bay's overall ecology have also been conducted by the Marine Biological Research Station (MBRS in Fig. 1b) of the South China Sea Institute of Oceanology, Chinese Academy of Sciences.

In this study, we are interested in: 1) changes in HABs over the past two decades; and 2) how such changes in environmental conditions in the bay area affect the frequency, area and location of HAB, algae species, as well as Chlorophyll $a$ concentration (Chl- $a$ ). In order to solve these questions, historical observations (1983 - 2004) and satellite remote sensing data were used to investigate the changes in $\mathrm{HAB}, \mathrm{Chl}-a$, nutrient and water surface temperature (WST). Results of this work should help better assess the impact of anthropogenic activities on marine environments in the bay area. 


\section{STUDY AREA AND METHODS}

\subsection{Study Area}

Daya Bay is located at $22.5-22.9^{\circ} \mathrm{N}, 114.5-114.9^{\circ} \mathrm{E}$, covering an area of about $600 \mathrm{~km}^{2}$ with an irregular coastline and more than 50 islands inside the bay (Fig. 1b). It is rather shallow, with a maximum depth of $21 \mathrm{~m}$ and a mean depth of $11 \mathrm{~m}$. Located in a sub-tropical region, Daya Bay's annual mean air temperature is about $22^{\circ} \mathrm{C}$, with the coldest months being January February $\left(15^{\circ} \mathrm{C}\right)$ and the hottest months July - August $\left(28^{\circ} \mathrm{C}\right)$. As a semi-enclosed bay, currents in Daya Bay are dominated by tides, and the water circulation with the SCS is fairly slow. No major rivers discharge into Daya Bay (Xu 1989; Wang et al. 2004).

\subsection{In Situ Data}

The South China Sea Institute of Oceanology (SCSIO), Chinese Academy of Sciences, has one Marine Biological Research Station (MBRS in Fig. 1b) in Dapeng Cove (DC in Fig. 1b), and also has made a series of regular research surveys over twelve stations in Daya Bay since 1982 (Fig. 1b). These surveys have been conducted regularly in spring (April), summer (July), fall (October), and winter (January) every year, seawater temperature, Chl- $a$, nutrient, etc. were measured and recorded. In addition, our research group (Remote Sensing and Marine Ecology/Environment) also investigated HABs (including frequency, location, area, and algae species of HABs), water surface temperature (WST), Chl- $a$, and nutrient data from time to time during 2003 - 2006. In the present study, all data were obtained from series research cruises in Daya Bay (conducted by our research group and MBRS), the Chinese Ecosystem Research Network (CERN) and the "Annual Report of Daya Bay Environment Research", Chinese Academy of Sciences.

All parameters, biological, physical, and chemical, were measured following standard methods (SOC 1991). According to the water depth, water samples were collected in the surface layer at less than $5 \mathrm{~m}$, surface and bottom layer for 5-10 m, surface, middle, and bottom layer for more than $10 \mathrm{~m}$. Sampling depth and water temperature were measured in situ by a YSI 6600 multi-parameter water quality monitor. Nutrients were analyzed using a Skalar Sanplus Nutrient Auto-analyzer. Chl- $a$ concentration was tested by fluorescence spectrophotometric method after extraction with acetone $(90 \% \mathrm{v} / \mathrm{v})$ in the dark for $24 \mathrm{~h}$ at $4^{\circ} \mathrm{C}$.

A total of 4220 in situ data from 1983 to 2004, including HAB frequency (69 data), Chl- $a$ (766 data), nutrients (1132 data during 1986 - 2002), and WST (2253 data) were processed to monthly mean values for the entire Daya Bay. The monthly mean values were then processed to yearly mean values. For the $69 \mathrm{HAB}$ cases, magnitude, location, and area were compared between two decades: 1983 - 1993 and 1994 - 2004. In this study, we counted HABs as those reported to have produced toxins, caused harm to fish and other aquatic life, changed water color by the increase of algal concentration. Algal species of major HABs were investigated. The size of HABs were rarely recorded, especially for the first decade (1983 - 1993), while some HABs were just described as "large" or "small" with no reference to the actual size. We used triangles to indicate those HABs-area sizes and locations unknown. Monthly HAB occurrence, WST, and Chl- $a$ were also compared between the two periods (1983 - 1993 and 
1994 - 2004). Nutrients in this study included total inorganic nitrogen (TIN $=\mathrm{NO}_{3}-\mathrm{N}+\mathrm{NO}_{2}$ $\left.-\mathrm{N}+\mathrm{NH}_{4}-\mathrm{N} ; \mathrm{mg} \mathrm{l}^{-1}\right)$ and phosphate $\left(\mathrm{PO}_{4}-\mathrm{P} ; \mathrm{mg} \mathrm{l}^{-1}\right)$. The ratio of TIN/P was calculated by TIN $\left(\mathrm{mg} \mathrm{l}^{-1}\right) / \mathrm{PO}_{4}-\mathrm{P}\left(\mathrm{mg} \mathrm{l}^{-1}\right)$.

\subsection{Satellite Data}

Satellite sea surface temperature (SST) data were derived from the Moderate Resolution Imaging Spectroradiometer (MODIS) onboard Aqua. The Aqua satellite passes the Earth from south to north over the equator in the afternoon and views the entire Earth's surface every 1 to 2 days. MODIS standard Level 2 SST-4 micron products $(1 \times 1 \mathrm{~km}$; nighttime $)$ were processed to a monthly image of May 2004. MODIS data were provided by NASA's Ocean Color Working Group (http://oceancolor.gsfc.nasa.gov/) and processed using the SeaWiFS Data Analysis System (SeaDAS; Baith et al. 2001).

\section{RESULTS}

\subsection{Annual Variation of HAB Frequency, Chl- $a$, and WST}

Annual HAB occurrences in Daya Bay showed an increasing trend during 1983 - 2000, with two peaks (16 and 15 HABs) occurring in 1998 and 2000, respectively (Fig. 2b). During 2001 - 2004, HABs declined to 2 - 5 events for each year (Fig. 2b). In the whole observation period, only 14 HABs were reported in the first decade (1983 - 1993), while 55 HABs were recorded in the second decade (1994 - 2004).

Yearly mean Chl- $a$ concentrations in Daya Bay showed a rapid increase during 1984 2003, ranging from 1.3 (1993) to $6.2 \mathrm{mg} \mathrm{m}^{-3}$ (2003). In most years Chl- $a$ concentrations were higher than $2 \mathrm{mg} \mathrm{m}^{-3}$, especially after 1994. In 2003, Chl- $a$ concentrations reached $6.2 \mathrm{mg} \mathrm{m}^{-3}$, which was nearly 3 times that of values before 1994 (Fig. 2c).

Yearly mean WST during the period 1983 - 2004 ranged from $21.6(1986)$ to $26.6^{\circ} \mathrm{C}$ (1999; Fig. 2d). Linear regression analysis showed WST increased by $2.69^{\circ} \mathrm{C}$ from 1983 to 2004, with a slope of 0.14 (Fig. 2d). The earliest recorded yearly mean WST in Daya Bay was $22.9^{\circ} \mathrm{C}$ in 1960 - 1970 (Xu 1989). We noticed that WST's in 1983, 1990, and 1995 were lower than the regression line. This was because WST data in these years were sampled only in winter and spring months. WST's in 1989 were higher than the regression line, because WST data in this year were sampled only in summer months (Fig. 2d).

\subsection{Location, Size, and Species of HAB}

The HAB affected area (location and size) increased during the past two decades (1983 2004; Fig. 3). At the mouth of Dapeng Cove (DC) where the two NPS locate, 5 HABs were recorded during 1983 - 1993 (Fig. 3a). While during 1994 - 2004, no HAB was reported at the DC mouth and only 2 HABs appeared inside DC (Fig. 3b). In the coastal waters from Aotou to Baguang, the number of HAB increased remarkably from only 2 events prior to 1994 to 27 events post 1994 (Fig. 3). The size of HABs in Daya Bay was also greater. During 1983 - 
1993, 2 HABs were recorded as covering a "large area" without a definite size of the area being described (Fig. 3a). In contrast, during 1994 - 2004 at least 3 HABs with large-area ( areas $\geq 100 \mathrm{~km}^{2}$ ) broke out in Daya Bay, including the largest area HAB $\left(242 \mathrm{~km}^{2}\right)$ on $10-13$ July 2001 (Fig. 3b). There were another 3 HABs (1983 - 1993) and 11 HABs (1994 - 2004); the sizes and exact locations of which were not recorded (Triangle in Fig. 3).

There are about 14 species that have caused HABs frequently in Daya Bay (Table 1), the major causative species were Scrippsiella trochoidea (8 times), Rhizosolenia sp. including Rhizosolenia alta forma gracilima and Rhizosolenia fragillissima (8 times), and Pseudo-nitzschia sp. including Pseudo-nitzschia pungens and Pseudo-nitzschia delicatissima (6 times). Major

(a) $1983-1993$

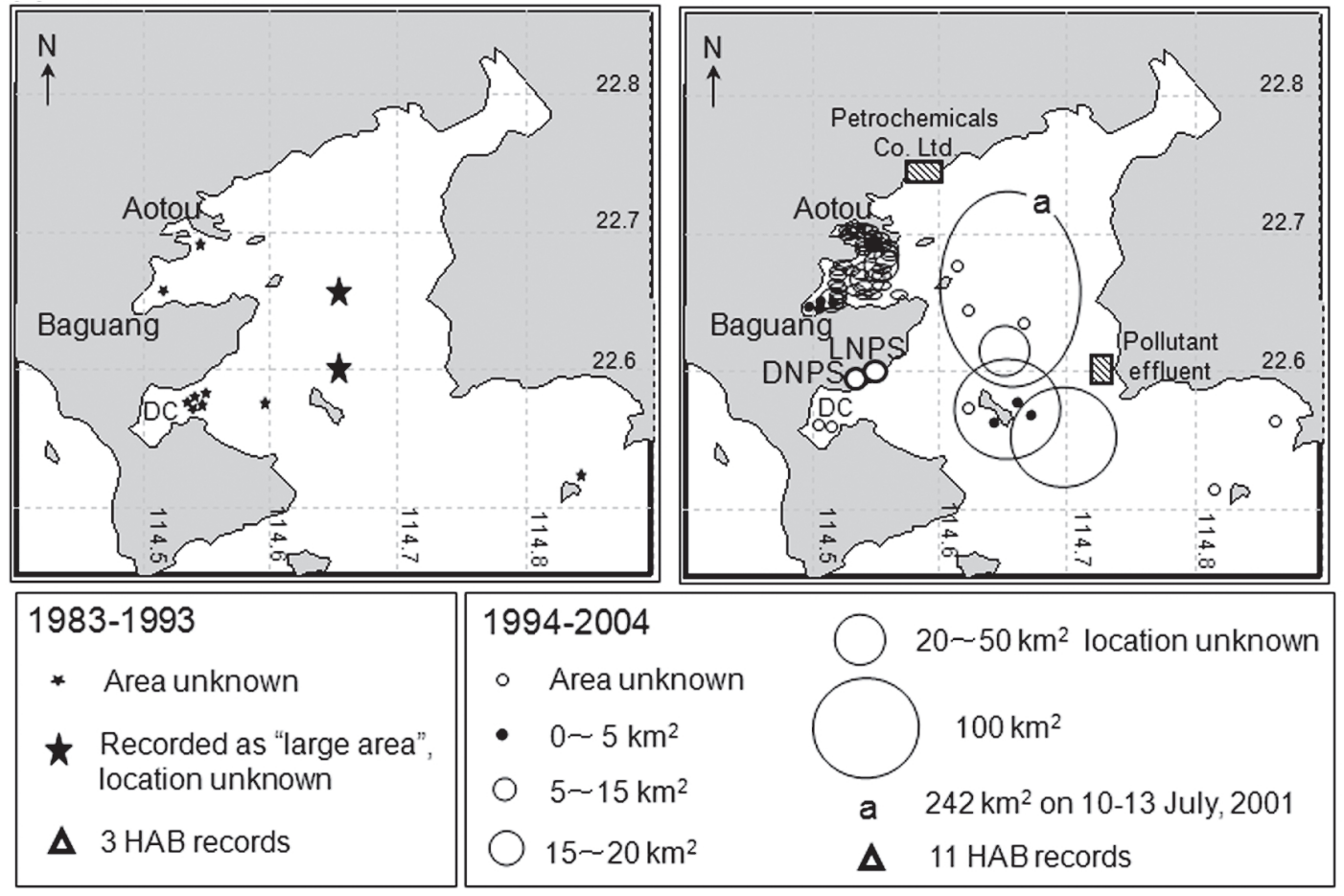

Fig. 3. Location and area of HAB for two periods: (a) 1983 - 1993 and (b) 1994 - 2004. Each asterisk represents one HAB during the period 1983 - 1993; each circle indicates one HAB during the period 1994 - 2004. The size of the asterisk and circle corresponds to the area of HAB. Circle " $a$ " depicts the largest area $\mathrm{HAB}$ with $242 \mathrm{~km}^{2}$ on 10 - 13 July 2001. Triangle indicates $\mathrm{HAB}$ events without a record of the size of area and exact location; these HABs were not indicated in the maps. 


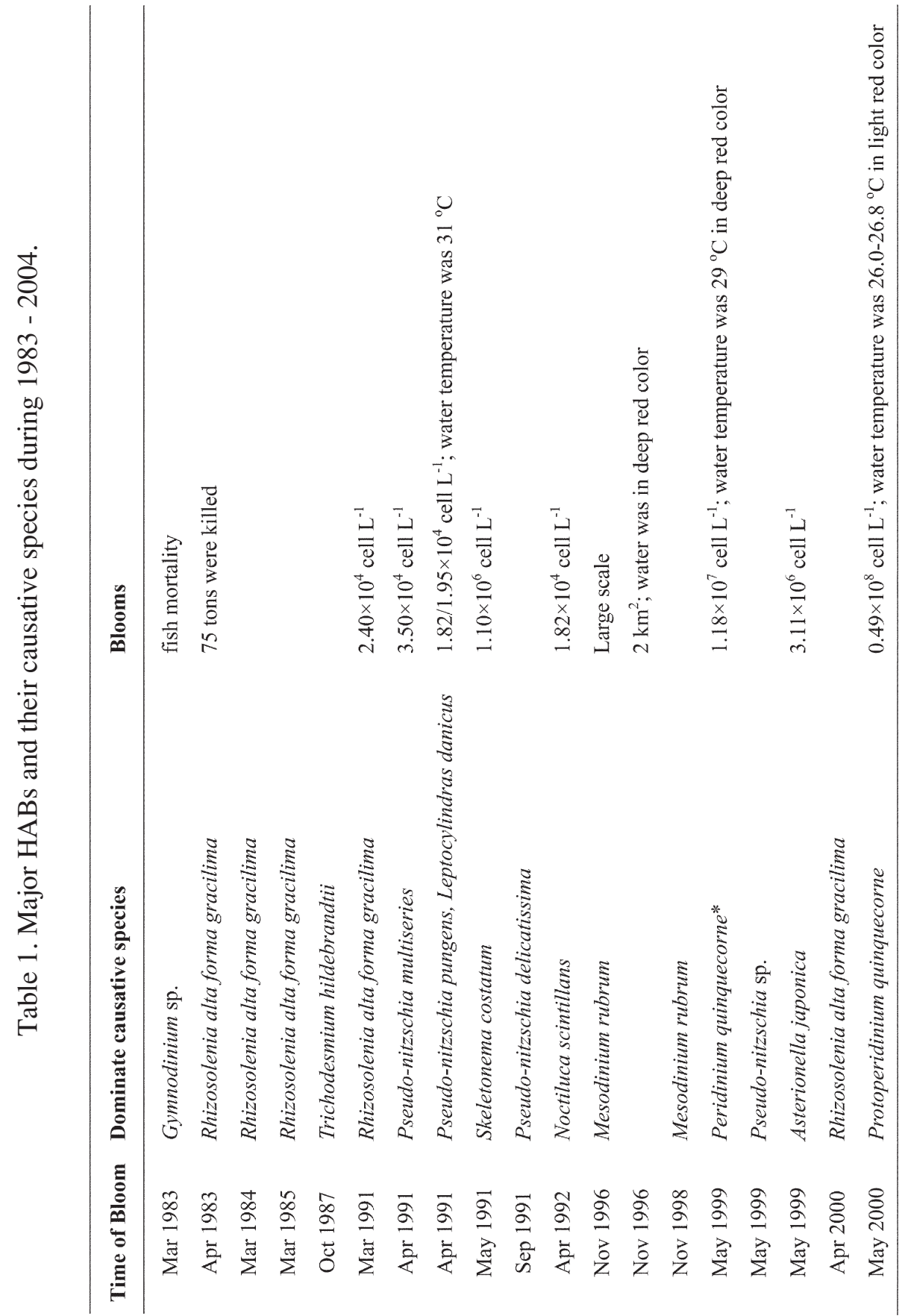


Yu et al.

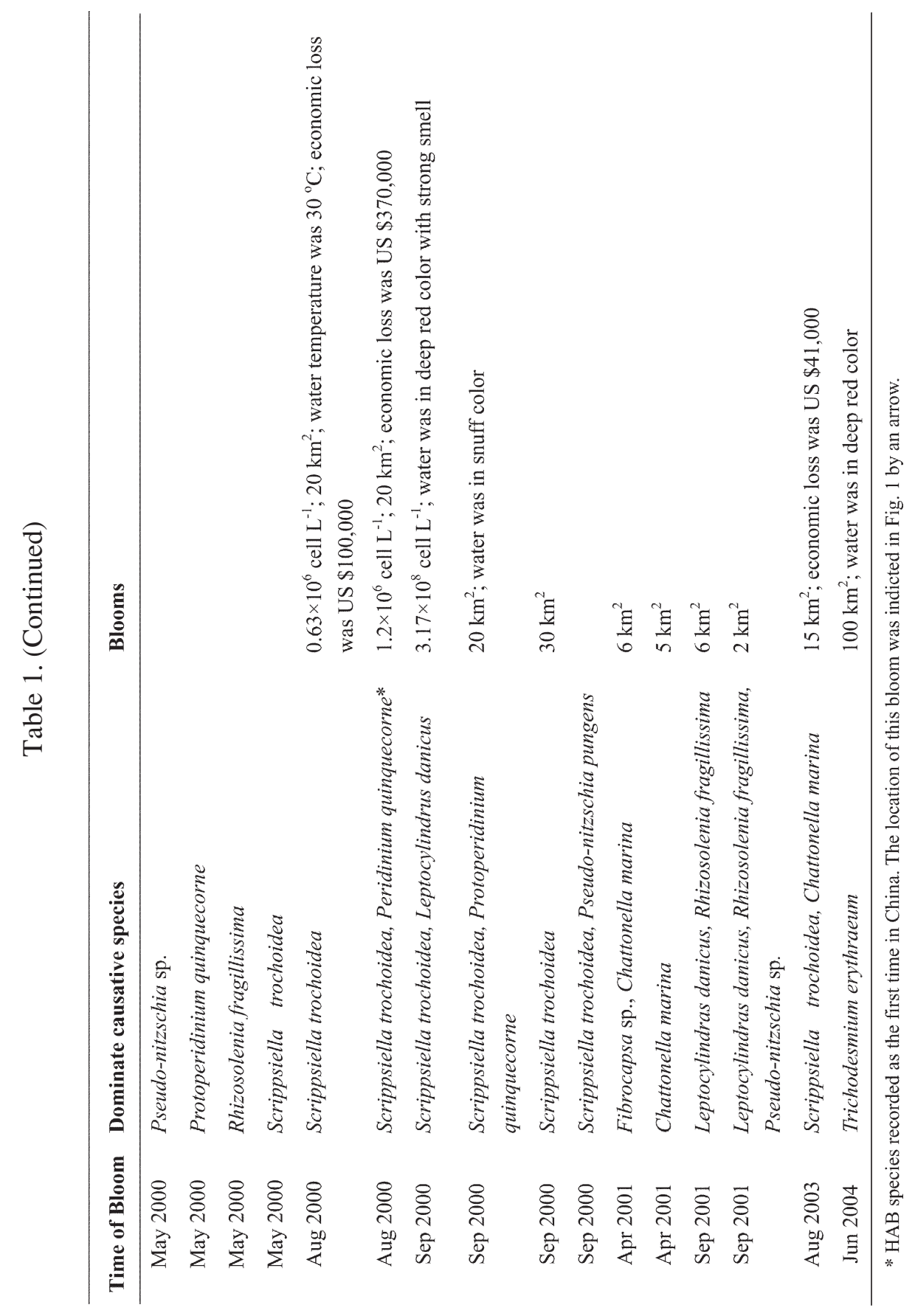


HABs in Daya Bay were caused by diatom and dinoflagellate. During 1983 - 1993, 7 HAB species occurred, most of which were diatom. During 1994 - 2004, 11 HAB species appeared, with the equal occurrences of diatom and dinoflagellate. A HAB caused by Peridinium quinquecorne was observed in May 1999 in Daya Bay when the water temperature was about $29^{\circ} \mathrm{C}$; it was the first recorded occurrence of this species blooming in China (Chen et al. 2000). This new species also caused a HAB in August 2000 while water temperature was relatively high (Table 1). For some HABs, algal abundance or the affected area were not recorded (Table 1).

\subsection{Seasonal Changes of HABs, Water Temperature, and Chl-a}

Comparison for HAB seasonality between the two decades showed an extending situation: During 1983 - 1993 HABs appeared mainly in spring and autumn months, while during 1994 2004 HABs occurred all year round ( $a$ and $b$ in Fig. 4a). In most months, HAB events post 1994 (1994 - 2004; b in Fig. 4a) were more than that prior to 1994 (1983 - 1993; a in Fig. 4a) with a significant increase in May, when WST and Chl- $a$ concentrations also increased a lot (c in Fig. 4a, Figs. 4b, c).

In order to analyze the relation between the increase of WST and HAB seasonality, the changes in monthly mean WST between the two periods, prior to and post 1994 when the DNPS began operation (Delta WST), were analyzed (c in Fig. 4a). Delta WST ranged from 0.2 (June) to $2.7^{\circ} \mathrm{C}$ (May), showing WST increased in each month except in March. It was noticed that monthly mean WST in March prior to 1994 was lower than that post 1994 (delta WST $<0^{\circ} \mathrm{C}$ ). This may be partly because of a cold wave in the spring of 1995, leading to decreased water temperature in March of that year (http://www.cma.gov.cn/). Our cruises were conducted mainly in January, April, July, and October; therefore, relatively few data were obtained in March. Prior to 1994, fewer surveys were conducted.

Delta WST showed some positive correlation with the extension of HAB seasonality (Fig. 4a). It was higher in the winter and spring months (November to May except March) compared to summer months (June to September), coinciding with the increase in HABs in winter and spring months. The peak value of delta WST occurred in May, when the increase in HABs was largest (Fig. 4a).

Monthly mean WST and Chl- $a$ increased during the second period (1994 - 2004), especially for Chl- $a$; for which, remarkable increases were observed each month (Figs. $4 \mathrm{~b}, \mathrm{c}$ ). The increase of monthly mean WST was relatively high in the winter months (November to February), ranging from 0.3 to $2.3^{\circ} \mathrm{C}$. The seasonality of monthly mean Chl- $a$ also changed, the peak value $\left(2.9 \mathrm{mg} \mathrm{m}^{-3}\right)$ in June and the lowest value $\left(1.4 \mathrm{mg} \mathrm{m}^{-3}\right)$ in January during the first decade (1983 - 1993) shifted to a peak value $\left(7.2 \mathrm{mg} \mathrm{m}^{-3}\right)$ in May and the lowest value $\left(2.2 \mathrm{mg} \mathrm{m}^{-3}\right)$ in February during the second decade (1994 - 2004; Fig. 4c).

Monthly SST image for May 2004 showed thermal plumes near the two nuclear power stations with $8-9^{\circ} \mathrm{C}$ higher water temperature than the ambient waters (Fig. 5).

\subsection{Changes in Environmental Conditions}

Yearly mean total inorganic nitrogen $\left(\mathrm{TIN}=\mathrm{NO}_{3}-\mathrm{N}+\mathrm{NO}_{2}-\mathrm{N}+\mathrm{NH}_{4}-\mathrm{N}\right)$, phosphate 
$\left(\mathrm{PO}_{4}-\mathrm{P}\right)$, and the ratio of TIN/P in Daya Bay were compared during 1986 - 2002 (Fig. 6). The ratio of TIN/P showed a rapid increase trend from 0.62 (1986) to 18.28 (1999), after 1999 it started to decline but still kept a higher level than that before 1994 (Fig. 6a). Total inorganic nitrogen (TIN) also enhanced from 0.021 (1986) to $0.068 \mathrm{mg} \mathrm{l}^{-1}$ (1999) and kept this high level after 1999 (Fig. 6b). In contrast, phosphate $\left(\mathrm{PO}_{4}-\mathrm{P}\right)$ decreased from 0.035 (1986) to $0.004 \mathrm{mg} \mathrm{l}^{-1}$
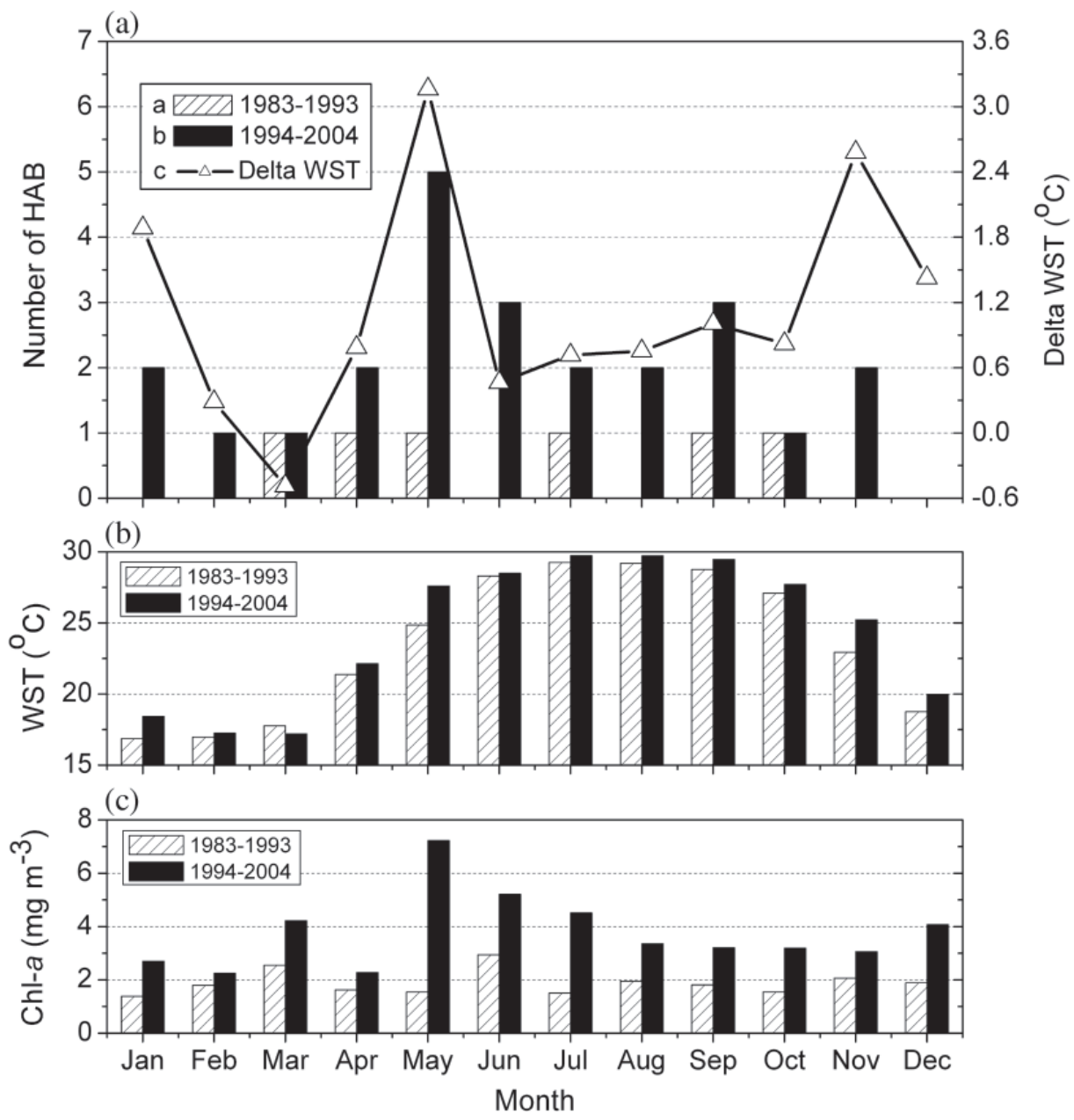

Fig. 4. (a) Comparison of monthly occurrences of HAB between two periods: (1) 1983 - 1993 and (2) 1994 - 2004. (3) Triangles indicate monthly change of water surface temperature before and after 1994 (Delta WST). (b) Comparison for monthly mean WST between two periods: 1983 1993 and 1994 - 2004. (c) Comparison for monthly mean Chl- $a$ between two periods: 1983 - 1993 and 1994 - 2004. Arrows indicate the month when the increase in HAB frequency, WST, and Chl- $a$ were largest. 
MODIS-SST $\left({ }^{\circ} \mathrm{C}\right)$

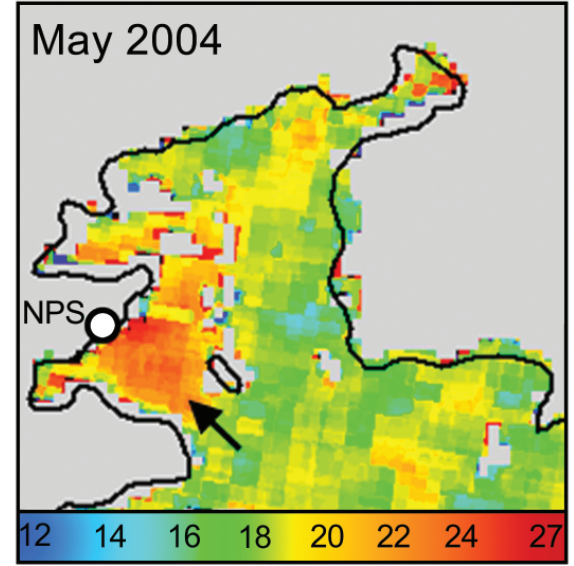

Fig. 5. MODIS-derived SST image $(1 \times 1 \mathrm{~km})$ for May 2004, showing the thermal plume from NPS. NPS: two nuclear power stations including DNPS and LNPS.

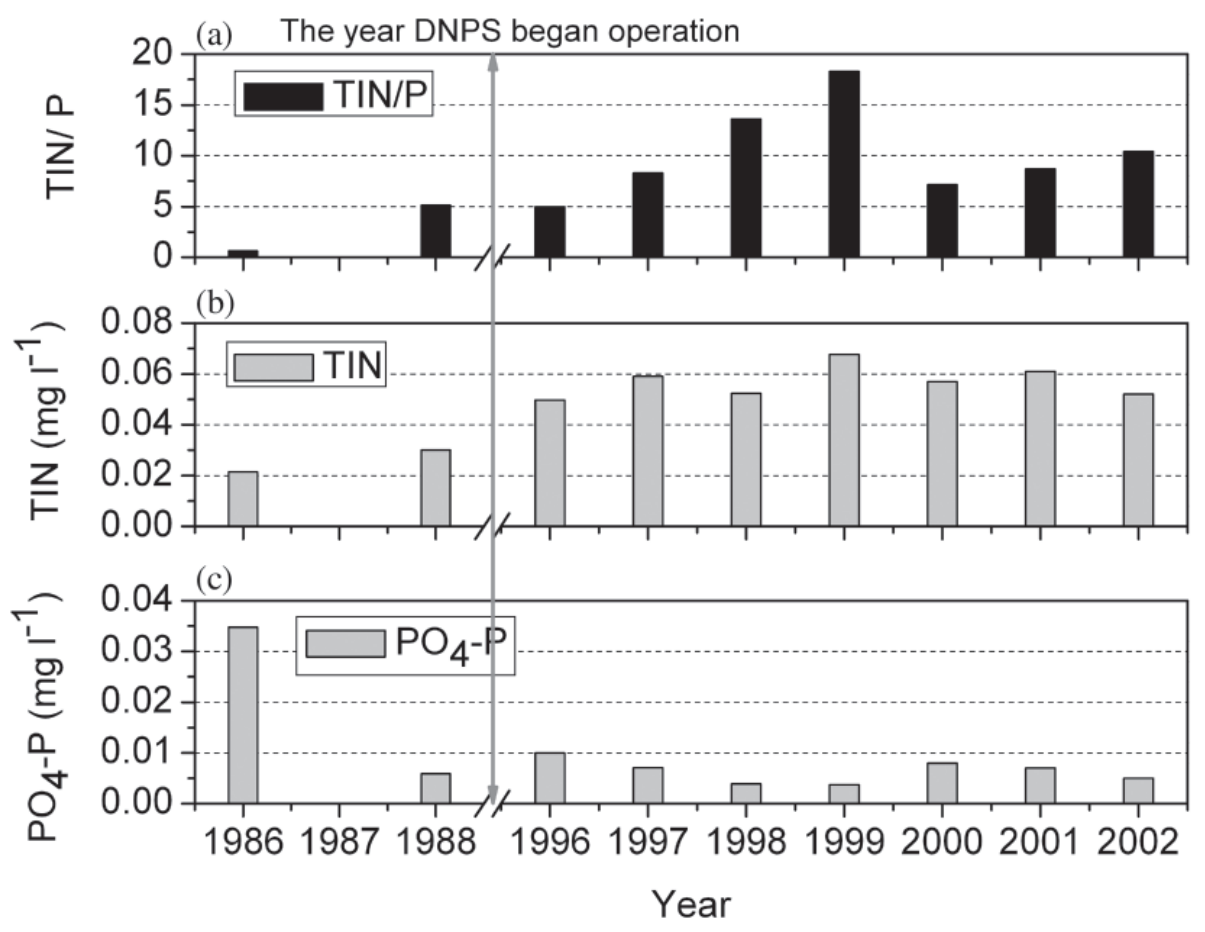

Fig. 6. Yearly mean nutrients in Daya Bay seawater from 1986 to 2002. (a) Average ratio of TIN/P $\left(\mathrm{TIN}=\mathrm{NO}_{3}-\mathrm{N}+\mathrm{NO}_{2}-\mathrm{N}+\mathrm{NH}_{4}-\mathrm{N} ; \mathrm{P}: \mathrm{PO}_{4}-\mathrm{P}\right)$; (b) total inorganic nitrogen (TIN) concentration; (c) phosphate $\left(\mathrm{PO}_{4}-\mathrm{P}\right)$ concentration. Grey line indicates the year when the first nuclear power station (DNPS) began operation. Blank indicates no data for the period (1987, 1989 - 1995). 
(1999) and maintained a low level after 1999 (Fig. 6c).

\section{DISCUSSIONS}

\subsection{Increases of HABs Associated with Nutrients and Water Temperature}

The frequency and affected area of HABs in Daya Bay increased after 1994 (Figs. 2b, 3), coinciding with elevated nitrogen nutrients and the ratio of TIN/P in the bay area (Fig. 6b). During 1983 - 1993, the nitrogen nutrients in Daya Bay were relatively low and only a little cage aquaculture was occurring in the sub-bays (Figs. 2a, 6). Consequently, only a few small HABs occurred with limited extent and Chl- $a$ concentrations were relatively low for the entire bay (Figs. 2b, c, 3a). But during 1994 - 2004, cage aquaculture in Daya Bay developed rapidly (Fig. 2a), leading to increased nitrogen nutrients and the ratio of TIN/P (Fig. 6). At the same time, more extensive HABs appeared in Daya Bay, particularly for those enclosed sub-bays such as Aotou and Baguang, where increased cage aquaculture was most noticeable (Figs. 2b, $3 b)$.

Prior to 1994, HABs localized mainly in the sub-bays such as Dapeng Cove, Aotou, and Baguang (Fig. 3a). After 1994, eutrophication of the bay's water had occurred to such an extent as a result of increased cage aquaculture that $\mathrm{HABs}$ began affecting more and more regions of the bay (Fig. 6). Noteworthy, however, was that waters very near the nuclear power stations had fewer HABs. The possible reasons are: 1$)$ the water temperature in this area is too high (8 $9^{\circ} \mathrm{C}$ higher than ambient waters; Fig. 5); and 2) entrainment effects (Bamber et al. 2004) and the usage of chemicals in cooling systems for controlling biofouling, scale deposits, or corrosion (Brook and Barker 1972).

Besides aquaculture other sources of pollutants that contribute to europhication of the bay include increased contaminants from industrial wastewater, sewage discharges and oil residues, all of which have adverse effects on the Daya Bay environment (He et al. 2001; Zhou and Maskaoui 2003). Eutrophication has become an important factor contributing to the increase in HAB frequency, location and overall extent.

Major HAB causative species in the Day Bay area (Table 1) were Scrippsiella trochoidea, Rhizosolenia sp., and Pseudo-nitzschia sp.. Scrippsiella trochoidea was also the major HAB species in the northern SCS (Wang et al. 2007). It was noticed that Peridinium quinquecorne caused a bloom in May 1999 in Daya Bay (arrow in Fig. 1), this was the first recorded occurrence of this species blooming in China (Chen et al. 2000). This species has a high water temperature tolerance $\left(42^{\circ} \mathrm{C}\right.$; Horstmann 1980), and tends to bloom in hot environments; it has caused HAB in Maribago Bay in Malaysia (Horstmann 1980) and South Africa (Horiguchi and Pienaar 1991). This warm-favoring species Peridinium quinquecorne blooms were observed in Daya Bay in both May 1999 and August 2000 (Table 1), when air temperature was rather high $\left(30.4^{\circ} \mathrm{C}\right)$ and water temperature had reached $29-30^{\circ} \mathrm{C}$. Those occurrences may indicate the response of algae to increased water temperature in Daya Bay.

\subsection{Seasonal Extension of HABs Related with Thermal Discharge from Nuclear Power} Stations 
It was noticed that very few HABs occurred in winter months (November to February) during 1983 - 1993, but during 1994 - 2004 HABs occurred all year round (Fig. 4a). This seasonal extension may be connected with an increase in water temperature after the operation of the first NPS (DNPS) in 1994.

The 18 Mkw DNPS and 40Mkw LNPS discharge thermal water into Daya Bay through one pipe at a rate of $190 \mathrm{~m}^{3} \mathrm{~s}^{-1}$. The thermal plume from the two NPS spreads many square kilometers (Tang et al. 2003b). MODIS satellite SST image of May 2004 observed high SST near to the NPS (black arrow in Fig. 5), showing thermal discharge from the NPS. Previous study observed that temperature elevation was $4^{\circ} \mathrm{C}$ in the waters $1 \mathrm{~km}$ away from the NPS, and $0.5^{\circ} \mathrm{C}$ in the waters $5 \mathrm{~km}$ away from the NPS (Zeng et al. 2002). Peng et al. (2001) reported that WST in Daya Bay increased by $0.77^{\circ} \mathrm{C}$ from 1993 to 1998 and the average warming rate was $0.128^{\circ} \mathrm{C}^{-1}$. The present study observed for a longer period and a similar result was obtained: yearly mean WST increased by $2.69^{\circ} \mathrm{C}$ from 1983 to 2004 and the average warming rate was $0.122^{\circ} \mathrm{C} \mathrm{y}^{-1}$. During the past fifty years (mid-1950s to mid-1990s), the global mean ocean temperature had increased by $0.31^{\circ} \mathrm{C}$ (Levitus et al. 2000). The increase in water temperature in Daya Bay was higher than the global average, partly because of the thermal discharge from the two NPS (Fig. 2d). Daya Bay is a semi-enclosed bay, and its water circulation with the SCS is rather slow (Xu 1989). The DNPS has been discharging warm water into the bay for more than 10 years since 1994, and bays generally have amplified responses to environmental changes than open water bodies (Mustard et al. 1999; Fox et al. 2000). All of these factors may have enhanced variations in water temperature in Daya Bay.

Water temperature used to be lower in winter months (November to February) in Daya Bay, but it increased after 1994, possibly making the water conditions more favorable to algal growth (Fig. 4a). It was noticed that monthly WST, Chl- $a$ concentration and HAB occurrence increased a lot in May after 1994 (Fig. 4), indicating May maybe a sensitive period for marine ecosystems in Daya Bay. This calls for more investigations and analysis.

\section{CONCLUSIONS}

This is the first study to analyze HABs and related environmental conditions in Daya Bay through both in situ measurements and satellite remote sensing over such a long term from 1983 to 2004. HABs were found to occur in higher frequency and to be more extensive both in terms of their absolute size and locations throughout the bay area after 1994; this seems to be directly related to elevated nitrogen nutrients and other contaminants in the bay. Most importantly, seasonality of HABs changed from being spring and autumn events prior to 1994 to becoming prevalent all year round post 1994. The major contributing factor here appears to be increased water temperature due to thermal discharge from the two nuclear power stations (DNPS and LNPS).

There were about 14 species of major HABs in Daya Bay, the number of HAB species increased after 1994. A new warm-favoring species (Peridinium quinquecorne) bloomed in 1999 and 2000, this may indicate the role increased water temperature is having in HABs. HABs are multifactor (including nutrients, water temperature etc.) events. Recent economic developments in industry, aquaculture, and agricultural activities have affected the marine 
environments of Daya Bay. In Daya Bay, May is a sensitive month for water temperature, Chl- $a$, and $\mathrm{HAB}$, particularly post 1994.

Acknowledgements This study was jointly supported by the following research grants to Professor Dan-Ling TANG: (a) Guangdong Natural Science Foundation (05102008 and 04001306), China; (b) Chinese Academy of Sciences (CAS) (Key Innovation Project KZCX3SW-227-3 and the One-Hundred Talents Program); and (c) National Natural Science Foundation of China (40576053). This work was also supported by projects from South China Sea Fisheries Research Institute, Chinese Academy of Fishery Sciences (2007TS10 and 2007ZD03), the High-tech Research and Development Program of China (2006AA100303), and the Korea Hydro \& Nuclear Power Co., Ltd (No. E045027002). The authors are grateful to the Chinese Ecosystem Research Network (http://www.cerndata.ac.cn), Marine Biological Research Station (MBRS; http://www.scsio.ac.cn/mbrs/index.htm), Dr. J. S. Lian of SCSIO, and Dr. G. F. Wei of Jinan University for their assistance in providing data.

\section{REFERENCES}

Anderson, D. M., 1994: Red tides. Sci. Am., 271, 52-58.

Anderson, D. M., 1995: Toxic red tides and harmful algal blooms: A practical challenge in coastal oceanography. US National Report to the IUGG American Geophysical Union, 1189-1200.

Anderson, D. M., 1998: Study of red tide monitoring and management in Hong Kong: Literature review and background information. Technical report No. 1., Hong Kong agricultural and fisheries department, Hong Kong, $115 \mathrm{pp}$.

Baith, K., R. Lindsay, G. Fu, and C. R. McClain, 2001: SeaDAS: Data analysis system developed for ocean color satellite sensors. EOS, Trans., AGU, 82, 202.

Bamber, R. N., and R. M. H. Seaby, 2004: The effects of power station entrainment passage on three species of marine planktonic crustacean, Acartia tonsa (Copepoda), Crangon crangon (Decapoda) and Homarus gammarus (Decapoda). Mar. Environ. Res., 57, 281-294, doi: 10.1016/j.marenvres.2003.08.002.

Brook, A. J., and A. L. Barker, 1972: Chlorination at power plants: Impact on phytoplankton productivity. Science, 176, 1414-1415.

Chen, J. F., Y. Z. Qi, Y. Z. Xiao, N. Xu, and J. R. Li, 2000: A new red tide species found Peridinium quinquecorne Abe in South China Sea. Mar. Environ. Sci., 19, 20-23. (in Chinese)

Fox, M. F., D. R. Kester, J. E. Andrews, A. Magnuson, and C. G. Zoski, 2000: Seasonal warming of Narragansett Bay and Rhode Island Sound in 1997: Advanced very high resolution radiometer sea surface temperature and in situ measurements. J. Geophys. Res., 105, 22071-22082.

He, X. Q., G. X. Zhang, Q. H. Zheng, W. C. Du, and W. Y. Wen, 2001: Analysis and assessment of the content of four heavy metals in the benthons in Daya Bay. Sci. Geograph. Sin., 21, 282-285. (in Chinese) 
Horiguchi, T., and R. N. Pienaar, 1991: Ultrastructure of a marine dinoflagellate, Peridinium quinquecorne Abé (Peridiniales) from South Africa with particular reference to its chrysophyte endosymbiont. Bot. Mar., 34, 123-131.

Horstmann, U., 1980: Observations on the peculiar diurnal migration of a red tide Dinophyceae in tropical shallow waters. J. Phycol., 16, 481-485.

Levitus, S., J. I. Antonov, T. P. Boyer, and C. Stephens, 2000: Warming of the world ocean. Science, 287, 2225-2229.

Mustard, J. F., M. A. Carney, and A. Sen, 1999: The use of satellite data to quantify thermal effluent impacts. Estuar. Coast. Shelf. S., 49, 509-524.

Peng, Y. H., H. R. Chen, M. X. Pan, H. H. Huang, and H. L. Gao, 2001: The primary production and potential fishery production in the sea area around the Daya Bay Nuclear Power Station before and after the operation of DBNPS. J. Fish. China, 25, 161-165. (in Chinese)

Qi, Y. Z., J. F. Chen, Z. H. Wang, N. Xu, Y. Wang, P. P. Shen, S. H. Lu, and I. J. Hodgkiss, 2004: Some observations on harmful algal bloom (HAB) events along the coast of Guangdong, southern China in 1998. Hydrobiologia, 512, 209-214.

Qian, H. L., S. Liang, and Y. Z. Qi, 2000: Study of the characteristics and the causes of formation on the red tides in coastal Guangdong sea. Ecol. Sci., 19, 8-16. (in Chinese)

SOC (State Oceanic China), 1991: The criterion of marine monitoring. Oceanographical Press, Beijing, 4-91. (in Chinese)

Song, X. Y., L. M. Huang, J. L. Zhang, X. P. Huang, J. B. Zhang, J. Q. Yin, Y. H. Tan, and S. Liu, 2004: Variation of phytoplankton biomass and primary production in Daya Bay during spring and summer. Mar. Pollut. Bull., 49, 1036-1044.

Tang, D. L., D. R. Kester, I. H. Ni, Y. Z. Qi, and H. Kawamura, 2003a: In situ and satellite observations of a harmful algal bloom and water condition at the Pearl River Estuary in late autumn 1998. Harmful Algae, 2, 89-99.

Tang, D. L., D. R. Kester, Z. D. Wang, J. S. Lian, and H. Kawamura, 2003b: AVHRR satellite remote sensing and shipboard measurements of the thermal plume from the Daya Bay, Nuclear Power Station, China. Remote Sens. Environ., 84, 506-515.

Tang, D. L., H. Kawamura, T. V. Dien, and M. A. Lee, 2004: Offshore phytoplankton biomass increase and its oceanographic causes in the South China Sea. Mar. Ecol. Prog. Ser., 268, 31-41.

Tang, D. L., B. P. Di, G. Wei, I. H. Ni, I. S. Oh, and S. F. Wang, 2006a: Spatial, seasonal and species variations of harmful algal blooms in the South Yellow Sea and East China Sea. Hydrobiologia, doi: 10.1007/s10750-006-0108-1.

Tang, D. L., H. Kawamura, I. S. Oh, and J. Baker, 2006b: Satellite evidence of harmful algal blooms and related oceanographic features in the Bohai Sea during autumn 1998. Adv. Space Res., 37, 681-689.

Wang, S. F., D. L. Tang, F. L. He, Y. Fukuyo, and R. V. Azanza, 2008: Occurrences of Harmful Algal Blooms (HABs) associated with ocean environments in the South China Sea. Hydrobiologia, 596, 79-93.

Wang, Y. S., Z. D. Wang, and L. M. Huang, 2004: Environment changes and trends in Daya Bay in recent 20 years. J. Trop. Oceanogr., 23, 85-95. (in Chinese) 
Xu, G. Z., 1989: Environments and resources of Daya Bay. Anhui Science Publishing House, Hefei, 6-9. (in Chinese)

Zeng, P., H. Q. Chen, B. C. Ao, P. Ji, X. J. Wang, and Z. L. Ou, 2002: Transport of waste heat from a nuclear power plant into coastal water. Coast. Eng., 44, 301-319.

Zhou, J. L., K. Maskaoui, Y. W. Qiu, H. S. Hong, and Z. D. Wang, 2001: Polychlorinated biphenyl congeners and organochlorine insecticides in the water column and sediments of Daya Bay. China. Environ. Pollut.. 113, 373-384.

Zhou, J. L., and K. Maskaoui, 2003: Distribution of polycyclic aromatic hydrocarbons in water and surface sediments from Daya Bay, China. Environ. Pollut., 121, 269-281.

Yu, J., D. L. Tang, I. S. Oh, and L. J. Yao, 2007: Response of Harmful Algal Blooms to environmental changes in Daya Bay, China. Terr. Atmos. Ocean. Sci., 18, 1011-1027, doi: 10.3319/TAO.2007.18.5.1011(Oc). 